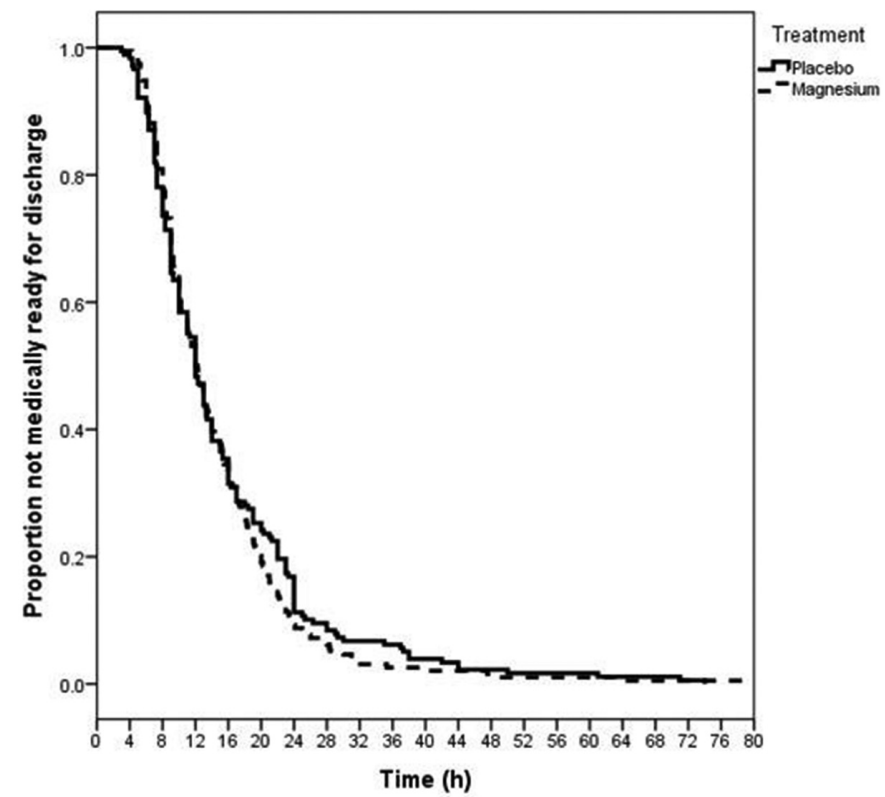

Abstract 0-203a Figure 2

(SD 0.06) $\mathrm{mmol} / \mathrm{L}, \mathrm{p}=0.001)$. There were no important adverse effects. However, accelerated failure time analysis showed a nonsignificantly shortened time to medical readiness for discharge of $14 \%$ favouring the magnesium sulfate group, OR $=1.14,95 \% \mathrm{CI}$ 0.93 to $1.40, \mathrm{p}=0.20$. Mean times until readiness for discharge were $14.6 \mathrm{~h}$ [SD 9.7] vs $15.6 \mathrm{~h}$ [SD 11.3] for the investigational and placebo groups, respectively, $\mathrm{p}=0.9$.

Conclusions Adding nebulized magnesium sulfate to combined nebulized bronchodilator and systemic steroid therapy fails to provide evident benefit for patients with moderate or severe status asthamticus.

\section{0-203b PAEDIATRIC MICRODOSE STUDY OF [14C] PARACETAMOL TO STUDY DRUG METABOLISM USING ACCELERATED MASS SPECTROMETRY: PROOF OF CONCEPT}

${ }^{1} \mathrm{MG}$ Mooij, ${ }^{2} \mathrm{E}$ van Duijn, ${ }^{3} \mathrm{CA}$ Knibbe, ${ }^{2} \mathrm{~W}$ Vaes, ${ }^{2} \mathrm{~B}$ Fabriek, ${ }^{4} \mathrm{AD}$ Windhorst, ${ }^{4} \mathrm{NH}$ Hendrikse, ${ }^{5} \mathrm{LM}$ Hanff, ${ }^{5} \mathrm{BCP}$ Koch, ${ }^{5} \mathrm{PJJ} \mathrm{M}$. Janssen, ${ }^{1} \mathrm{D}$ Tibboel, ${ }^{1} \underline{\mathrm{S} \text { de Wildt. }}{ }^{1}$ Department of Pediatric Surgery and Intensive Care, Erasmus University Medical Center - Sophia Children's Hospital, Rotterdam, Netherlands; ${ }^{2}$ Innovation for Life, TNO, Zeist, Netherlands; ${ }^{3}$ Clinical Pharmacology, Leiden Academic Center for Drug Research, Leiden, Netherlands; ${ }^{4}$ Nuclear Medicine and PET Research, VU Medical Center, Amsterdam, Netherlands; ${ }^{5}$ Clinical Pharmacy, Erasmus MC, Rotterdam, Netherlands

\subsection{6/archdischild-2014-307384.273}

Rationale Microdosing is a promising new method to obtain pharmacokinetic data in children with minimal burden and minimal risk. The use of a labelled oral microdose offers the added benefit to study intestinal and hepatic drug disposition in children already receiving an intravenous therapeutic drug dose for clinical reasons.

Objective To present pilot data of an oral $\left[{ }^{14} \mathrm{C}\right]$ paracetamol (AAP) microdosing study as proof of concept for this method to study developmental pharmacokinetics in children.

Methods In an open microdose pharmacokinetic pilot study, infants $\left(0-6\right.$ yrs of age) received a single oral $\left[{ }^{14} \mathrm{C}\right] \mathrm{AAP}$ microdose $(3.3 \mathrm{ng} / \mathrm{kg}, 60 \mathrm{~Bq} / \mathrm{kg})$ in addition to intravenous therapeutic doses of AAP (15 mg/kg IV q6 h) prescribed by the treating physician to provide analgesia. Blood samples were taken from an indwelling catheter at multiple time points. AAP blood levels were measured by LC-MS/MS and $\left[{ }^{14} \mathrm{C}\right] \mathrm{AAP}$ and metabolites $\left(\left[{ }^{14} \mathrm{C}\right] \mathrm{AAP}-\mathrm{Glu}\right.$ and $\left.\left[{ }^{14} \mathrm{C}\right] \mathrm{AAP}-4 \mathrm{Sul}\right)$ were measured by accelerator mass spectrometry.

Results Ten infants (ranging from 0.1 to 83.1 months of age) were included, one patient was excluded from PK analysis, as he vomited shortly after administration. In all 9 patients, $\left[{ }^{14} \mathrm{C}\right] \mathrm{AAP}$ and metabolites in blood samples were detectable at expected concentrations. Dose normalised $\left[{ }^{14} \mathrm{C}\right] \mathrm{AAP} \mathrm{C}_{\max }$ concentrations approached median $\mathrm{C}_{\mathrm{av}}$ intravenous concentrations: median 8.41 $\mathrm{mg} / \mathrm{L}$ (range 3.75 to $23.78 \mathrm{mg} / \mathrm{L}$ ) and $8.87 \mathrm{mg} / \mathrm{L}$ (range 3.45 to $12.9 \mathrm{mg} / \mathrm{L})$, respectively.

Conclusions We demonstrate the practical and ethical feasibility to use a $\left[{ }^{14} \mathrm{C}\right]$ labelled microdose to study paracetamol pharmacokinetics, including metabolite disposition, in young children.

\section{EAP - Investigators Presentations}

\section{0-204 AORTIC AND CAROTID DIMENSIONS AND INTIMA MEDIA THICKNESS IN 6-YEAR-OLD CHILDREN}

${ }^{1} \mathrm{~L}$ Mohlkert, ${ }^{2} \mathrm{C}$ Pegelow Halvorsen, ${ }^{3} \mathrm{~J}$ Hallberg, ${ }^{4} \mathrm{~A}$ Edstedt Bonamy, ${ }^{5} \mathrm{M}$ Norman. ${ }^{1}$ Departmeny of Clinical Science Intervention and Technology, Karolinska Institutet, Stockholm, Sweden; ${ }^{2}$ Department of Clinical Science and Education Södersjukhuset, Karolinska Institutet, Stockholm, Sweden; ${ }^{3}$ Institute of Environmental Medicine, Karolinska Institutet, Stockholm, Sweden; ${ }^{4}$ Department of Women's and Children's Health, Karolinska Institutet, Stockholm, Sweden; ${ }^{5}$ Department of Clinical Science Intervention and Technology, Karolinska Institutet, Stockholm, Sweden

\subsection{6/archdischild-2014-307384.274}

Background and aim Preterm birth has been associated with myocardial remodelling, arrested vascular growth, higher blood pressure and ventricular hypertrophy later in life. The aim of this study was to evaluate arterial dimensions and intima media thickness in 6-year-old children born extremely preterm.

Method Children born extremely preterm (EXP; $<27$ weeks of gestation) in Sweden 2004 to 2007 and matched controls born at term were included. The end-diastolic diameter of the abdominal aorta (AAD) and common carotid artery (CCAD) and carotid intima media thickness (CIMT) were determined by ultrasonography. Blood pressure, weight and height were also measured.

Results EXP-children ( $\mathrm{n}=88$; mean GA $25.1 \mathrm{w}$; BW 817 g) were significantly shorter than controls (mean heights 117.8 and $122.8 \mathrm{~cm}, \mathrm{p}<0.001)$. AAD was $8.8 \mathrm{~mm}$ in EXP and $8.9 \mathrm{mmin}$ controls (n.s). CCAD was larger $(5.5 \mathrm{~mm})$ in EXP than in controls $(5.2 \mathrm{~mm} ; \mathrm{p}<0.01)$ after adjusting for body surface area (BSA). CIMT was $0.62 \mathrm{~mm}$ in EXP and $0.54 \mathrm{~mm}$ in controls (p $<0.001$ ) adjusted for BSA. Unadjusted systolic blood pressure was $2.2 \mathrm{mmHg}$ lower in EXP compared to controls $(\mathrm{p}<0.05)$ but this difference disappeared after taking length into account.

Conclusion The CCAD but not the AAD was significantly wider and the carotid intima media was thicker in 6-year-old children born extremely preterm as compared to age matched controls at term.

Further vascular follow-up at older age is warranted and analyses of carotid strain using two dimensional speckle tracking are underway. 